\title{
Petrographic microscope investigation of mortar and ceramic technologies for the conservation of the built heritage.
}

\author{
S. Pavía* and S. Caro**. \\ *Dept of Civil, Structural and Environmental Engineering. Trinity College Dublin. \\ ${ }^{* *}$ Museo Paleontologico de Enciso, La Rioja, Spain.
}

\begin{abstract}
Polarised-light (or petrographic) microscopy has been widely applied to heritage materials to assess composition and diagnose damage. However, instead, this paper focuses on the petrographic investigation of brick and mortar technologies for the production of quality repair materials compatible with their adjacent fabrics. Furthermore, the paper relates production technologies to the physical properties of the materials fabricated, and thus their final quality and durability. According to Cesare Brandi's theory of compatibility (the 20th century architect on whose work modern conservation theory and practice are largely based) existing historic materials should be replaced with their equivalent. This paper demonstrates that polarised-light microscopy provides data on the origin and nature of raw materials, and processing parameters such as blending, mixing, firing, calcination and slaking, and how these relate to the quality of the final product. In addition, this paper highlights the importance of production technologies as these directly impact the physical properties of the materials fabricated and thus determine their final quality and durability. In this context, the paper investigates mortar calcination and slaking, two important operations in the manufacture of building limes that govern the reactivity, shrinkage and water retention of a lime binder which will impact mortar's properties such as workability, plasticity and carbonation speed, and these in turn will determine the ease of execution, durability and strength of a lime mortar. Petrographic analysis also provides evidence of ceramic technology including identification of local or foreign production and processing parameters such as sieving, blending, mixing and firing. A petrographic study of the ceramic matrix coupled to the diagnosis of mineral phases formed during firing allows to quantify sintering and vitrification and thus determine firing temperatures. Finally, certain features of the raw clay such as the grading and the amount and nature of the non-plastic material inform, not only on the raw material's origin, but also impact the physical properties of the ceramic ware.
\end{abstract}

Keywords: polarised-light (petrographic) microscopy, lime mortar, clay brick, production technology, origin, calcination, slaking, mixing, additions, firing, lime reactivity, shrinkage, water retention, workability, plasticity.

\section{INTRODUCTION}

The polarizing microscope, also known as petrographic microscope, is an important tool in geology and archaeology which can be used to identify sources of raw materials and to attribute stone and ceramic artefacts to their geological source. As with conventional microscopes, the objective enlarges the image and the eye piece magnifies the object further. However, the petrographic microscope differs in that it is equipped with two polaroids: a polarizer and an analyser, fitted above and below the specimen to examine specimens with transmitted polarized light using a light source below the stage. Minerals are identified by studying their optical properties, a graduated rotational stage allows angles to be measured and approximately twelve optical properties can be determined ${ }^{1}$. The technique of examining rocks in thin section using a polarising microscope was developed in the mid- $19^{\text {th }}$ century: it was found that a slice of rock, if ground sufficiently thin, becomes transparent, and thus amenable to microscopic examination. This technique was applied in the late 
19th century to archaeological problems, however, its first notable success in archaeology came later, when the 'blue stones' from Stonehenge were traced to a source in South-west Wales ${ }^{2}$.

Petrographic microscopy is an established technique for mortar analysis ${ }^{3,4}$. A petrographic study of a mortar informs on the composition, origin and proportions of the raw materials used for its fabrication. It enables to assess aggregate size and shape; presence of additions such as pozzolans; binder type and pore structure; current condition; decay processes such as fracturing, binder dissolution, aggregate/binder reaction and salt damage; and reasons for failure, thus providing valuable data to design improved mixes or mortar replicas for conservation works ${ }^{5}$. Rilem Technical Committee TC 167-COM (Characterisation of old mortars with respect of their repair), involved with the methodologies for the study of historic mortars that allow production of new repair mixes, highly considers petrographic microscopy (Hughes 2007 pers.com.).

Petrographic analysis is also an established method for ceramic investigation. It has been used by former authors (in conjunction with other analytical techniques of the physical sciences) to determine firing technologies, provenance and sources of raw materials of building ceramics ${ }^{6,7,8,9,10,11,12,13}$. Petrographic microscopy permits investigating the composition of the brick's temper and matrix and the presence of additions such as fuel. Petrographic analysis of the temper is a powerful method for the identification of local or foreign ceramic production, especially for coarse-grained ceramics. 'By definition, temper includes all phases with a diameter greater than $0.015 \mathrm{~mm}$. The temper can be added artificially (artificial temper) or present in the clay (natural temper) ${ }^{14}$. Furthermore, the study of the birefringence of the matrix and the amount of pores and cements, coupled to the petrographic identification of diagnostic minerals produced during firing, enable to quantify sintering and vitrification and thus estimate firing temperatures.

Polarised-light microscopy has been widely applied to heritage materials for the assessment of composition and to diagnose damage (Alastuey, Alesandrini, Alonso, Bakolas, Baronio, Bartos, Binda, Blanco-Varela, Caro, Charola, De la Torre, Delgado Rodrigues, Groot, Elsen, Esbert, Furlan, Fratini, Henriques, Hughes, Knöfel, Lazzarini, Laurenzi Tabasso, Moropoulou, Middendorf, Ordaz, Pavía, Puertas, Rodriguez Navarro, Schäfer, Valek, Van Hees, Veniale, Zehnder, Zezza and others), however, this technique also permits to investigate material production technologies and this is the purpose of this paper. The novelty of this paper resides in that it focuses on the petrographic investigation of brick and mortar technologies for the production of quality repair materials compatible with their adjacent masonry fabrics, simultaneously relating production technologies to the physical properties of the materials fabricated, and thus their final quality and durability.

\section{MATERIALS AND METHODS}

Thin section preparation for petrographic analysis often requires pre consolidation of friable material by impregnation in a resin under vacuum. The thin sections shown in this paper were first impregnated in resin and cut with oils to avoid damage to water-soluble minerals. The samples were also dyed with a chemical solution containing alizerine and potassium ferrocyanide in order to differentiate carbonate minerals. They were then polished to the standard thickness of 20 microns, covered with a glass slip and examined with a petrographic microscope incorporating eye pieces of 2, 10, 20 and 40 magnifications, using both natural and polarised light.

One of the limitations of petrographic analysis is that it is a destructive technique. In addition, it is often qualitative because quantitative calculation is laborious and limited, and this is due to both the large amount of observations needed in order to build up quantitative data, and the great variability of masonry materials in a single site. The polarised-light microscope is also limited by its resolution of approximately 1 micron $^{15}$. It provides a two-dimensional cross-sectional view of a $4-5 \mathrm{~cm}^{2}$ area, therefore, it is important that the samples are characteristic and representative of the building site subject to investigation ${ }^{15}$. A further limitation of this technique resides in the identification of certain organic compounds within mortars as these, once added to the mortars, become inorganic through mineralization, and thus they are not longer identifiable as organic additions with optical methods. 


\section{PETROGRAPHIC MICROSCOPY AND THE TECHNOLOGY OF LIME PRODUCTION}

Most building limes in Europe are currently produced industrialy, however, small-scale traditional production for specific works also occurs. Petrographic microscopy permits to investigate the technology of lime production, and this can be taken into account today in the traditional production of building limes.

Calcination and slaking are important operations in the manufacture of building limes. They impact lime binder properties including reactivity, shrinkage, density and water retention capacity which in turn will impact mortar's properties such as workability, plasticity and carbonation speed ${ }^{16}$, and these are important because they determine the ease of execution, durability and strength of a lime mortar. For example plastic, workable mortars are easy to work with while plastic, workable, water retentive mortars develop a strong bond with masonry units thus ensuring structural strength of masonry and sealing against weathering agents.

Leslie and Hughes ${ }^{17}$ provide a range of calcination temperatures based on the petrograhic and mineralogical analysis of high-temperature mortar slag formed in the kiln during firing, suggesting temperatures in excess of $1000^{\circ} \mathrm{C}$. However binder properties including reactivity, shrinkage, cohesion and fineness can also be analysed with petrographic microscopy providing important clues on lime calcination and slaking. For example, a cohesive lime binder with a high specific surface, low shrinkage and strong aggregate-binder bond coupled to the presence of aggregate-binder reaction denotes a high reactivity for the lime which agrees with soft burning (Figs. 1 and 2). According to Boyton ${ }^{16}$, burning temperature and duration govern the final properties of lime: lower burning temperatures and /or shorter burning duration (soft burning) yield the desirable soft-burned, highly reactive limes of low shrinkage and density and high porosity whereas high burning temperatures and long calcining periods result in hard-burned, dense quicklimes of high shrinkage, low porosity and low reactivity.

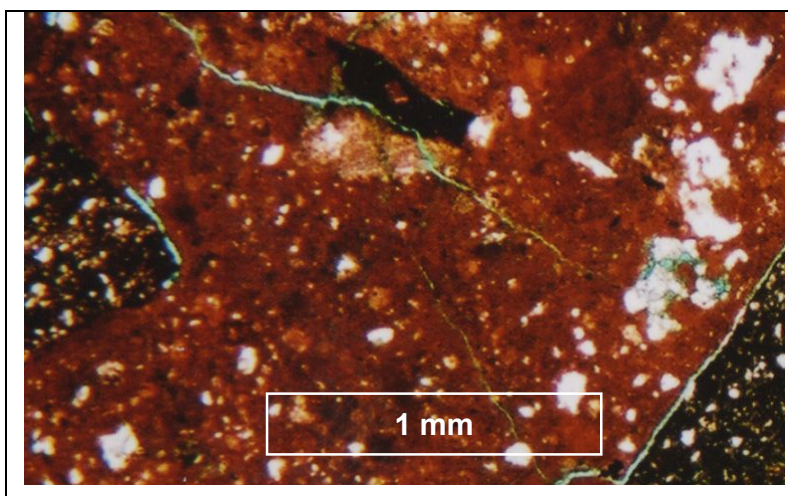

Figure 1. Roman lime mortar (Inestrillas, La Rioja, Spain) including a cohesive lime binder with high specific surface, low shrinkage and a strong aggregate bond typical of soft burning. Plane polars.

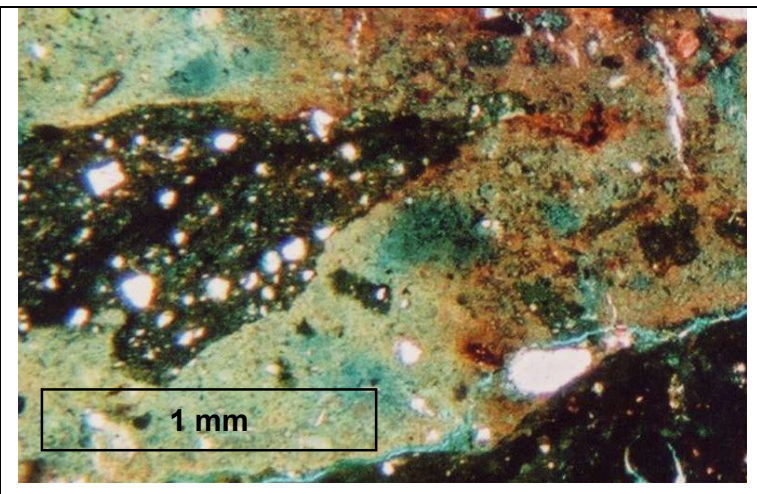

Figure 2. Roman lime mortar (Varea, La Rioja, Spain). Even, fine-grained, carbonated lime binder with no lime particles and an absence of shrinkage fractures, consistent with a long, full slaking. Plane polars.

Petrographic microscopy has evidenced that accumulations of lime binder (lime lumps) are a common feature of historic lime mortars (Fig.3). These have been reported throughout Europe in Britain, Finland, Ireland, Italy, Spain and other countries, and are due to the presence of unslaked lime, or weakly burned lime, or lime which has already hardened prior to use ${ }^{18}$. Their presence therefore indicates either a too short or an incorrect slaking (when a large water excess is rapidly added lime is 'downed', its surface becomes hydrated and impervious to water penetration and thus lumps are formed ${ }^{16}$ ). The presence of lime lumps can also indicate an incomplete calcination ${ }^{19}$, poor mixing ${ }^{20}$ or the practice of 'hot lime mixing ${ }^{21}$. In addition, these accumulations of lime binder often appear fractured under the microscope (Fig.3) due to the fact that pure calcium lime is a non-hydraulic binder with a high retraction coefficient. Aggregate is added to mortar in order 
to minimise retraction and avoid fracturing. Therefore, petrographic evidence of high binder/aggregate ratios, coupled to an absence of shrinkage fractures would be consistent with a high water-retention capacity for the lime as this avoids shrinkage fracturing due to a high or sudden evaporation (Fig.4).

Concerning slaking, it has been demonstrated that long slaking periods (during storage) improve the physical properties of lime including plasticity and workability, water retention capacity and carbonation speed ${ }^{22}$. These properties of the lime binder greatly affect the final quality and durability of a mortar: a high plasticity and workability enhance mortar mixing and execution, aggregate-binder adhesion and the quality of the bond between the mortar and the masonry unit; while a high water retention speeds up mortar hardening by carbonation. Based on these relationships, even, fully-carbonated, cohesive binder petrofabrics displaying a strong aggregate-binder bond and lacking from lime accumulations and shrinkage fractures would be consistent with a long, full slaking undertaken using a correct amount of water (Figs. 1, 2 and 4).

\section{PETROGRAPHIC MICROSCOPY VS LIME MORTAR TECHNOLOGY}

\subsection{Mixing}

In general, even petrofabrics suggest a through mixing whereas aggregate segregation evidences a lack of mixing. In particular, evidence of the practice of 'hot mixing' can be recorded microscopically. Hot mixing involves adding wet aggregate (or aggregate and water) to quicklime (unslaked lime powder) in order to make a mortar. This method implies that both mortar mixing and the exothermic reaction of lime slaking take place simultaneously. As a result, aggregate-binder reaction can be trigered by hot mixing (Fig.5), however, aggregate-binder reaction in lime mortars can also be the result of hydraulicity or weathering. Therefore, eventhough aggregate-binder reaction can suggest hot mixing, this needs to be contrasted with to further petrographic data. For example, Hughes and $\mathrm{Culbert}^{23}$ relate the presence of recarbonated, burned lime inclusions with no traces of the primary limestone to hot mixing.

\subsection{Mortar hydraulicity}

Hydraulicity of lime mortar can be due to the presence of either hydraulic binder or pozzolans, and pozzolans can be either naturally present or artificially added. Therefore, petrographic evidence of mortar hydraulicity can be gathered either by analysing the mineralogy of the lime binder (whether it fully consists of carbonate lime (calcite) or it includes hydraulic phases) or the presence of pozzolanic material such as reactive aggregate, ceramic dust or fossil fuel.

In some cases, the presence of a particular type of aggregate or underburned limestone particles within a mortar evidences the nature of a lime binder. For example, in the Roman mortars at the city of ContrebiaLeukade, Spain (Fig.6), the presence of clay-bearing tufa aggregate and clay flakes within the binder suggest that the local clay-bearing tufa was both used as aggregate and burned to produce hydraulic lime ${ }^{24}$.

As aforementioned, mortar hydraulicity can also be due to the presence of pozzolans, and these can be either naturally present (Fig. 7) or artificially added (Fig. 8). For example, reactive rock fragments with pozzolanic character can be naturally present in the aggregate (Fig. 7) whereas ceramic fragments were often added to lime mortars to induce a hydraulic set thus acting as pozzolans (Fig. 8). This was very common in Roman times however, in Europe, adding ceramic dust as a pozzolan was also a common practice in Medieval and postmedieval times. Pozzolanic reaction of brick dust in lime mortars has been recorded by several authors ${ }^{25,26}$

Fragments of fossil fuel are often recorded by petrographic analysis in historic lime mortars (Figs. 9 and 10). In some cases, their sporadic presence suggests that they are accidental, probably due to contamination from the kiln fuel used for the production of lime. This fact has been reported by a number of authors ${ }^{20,26,27}$. Some of these fuel fragments can react with the lime binder forming hydraulic cements (Fig. 10) therefore imparting 
a hydraulic set to the mortars ${ }^{26}$. However, there are exceptions to the sporadic occurrence of fuel, when this substance was deliberately added to the mortar as a pozzolan. Examples of this practice are the charcoal added to the $17^{\text {th }}$ century renders of Portumna Castle, Ireland, and coal added to the $18^{\text {th }}$ century render of Castlefield House, Ireland ${ }^{26}$

\subsection{Mortar additives and execution}

Petrographic analysis can also provide data on mortar execution. For example, organic fibres of hair, wood and straw are often found in medieval and postmedieval rendering mortars in Ireland ${ }^{26}$. These were added as structural reinforcement as well as to minimise fracturing by retraction. It has been reported in historic documents that substances such as eggs, dairy products, beer, syrup and starch were added to mortars to enhance workability or speed up carbonation. For example, Enoch ${ }^{28}$ reports that, in the $18^{\text {th }}$ century, blood was added to mortars in Ireland for the construction of Martello Towers. Over a period of time, these organic additions become inorganic compounds through mineralization, and thus they are not longer identifiable as organic additions with optical methods. However, in some mortars, the occurance and distribution of certain minerals can suggest the former presence of organic additives. For example, petrographic examination of the Booterstown Martello mortars ${ }^{26}$ evidenced an unusual feature: a binder interspersed with abundant microscopic crystals of haematite which may have generated through the mineralisation of the haemoglobine's iron in the blood reported to have been added to these mortars ${ }^{28}$.

Petrographic microscopy can also inform on problems on execution such as fracturing due to highly sorptive substrates (porous, highly sorptive substrates with excessive or rapid suction will draw water from a lime mortar causing the binder to fracture $)^{26}$.

\subsection{Sources of raw materials}

Both the aggregate composition and the presence of underburned limestone fragments in a mortar can inform on the provenance of the raw materials used for its fabrication. Historically, builders mainly used local sources of materials due to availability and ease of transportation. This can be evidenced with petrographic analysis in many case studies ${ }^{26}$. For example, in coastal areas the use of beach sand can often be determined by the morphology of the aggregate and the presence of sea shells (Figs 11 and 12). In other cases, the composition of the aggregate agrees with the geology of the area thus suggesting a local source (Figs 6 and 13). In addition, underburned limestone particles in mortars, remnants of the raw limestone burned to produce the lime, can evidence the raw limestone's quality thus suggesting a possible source (Figure 14). This has also been remarked by former authors ${ }^{21,29}$. 


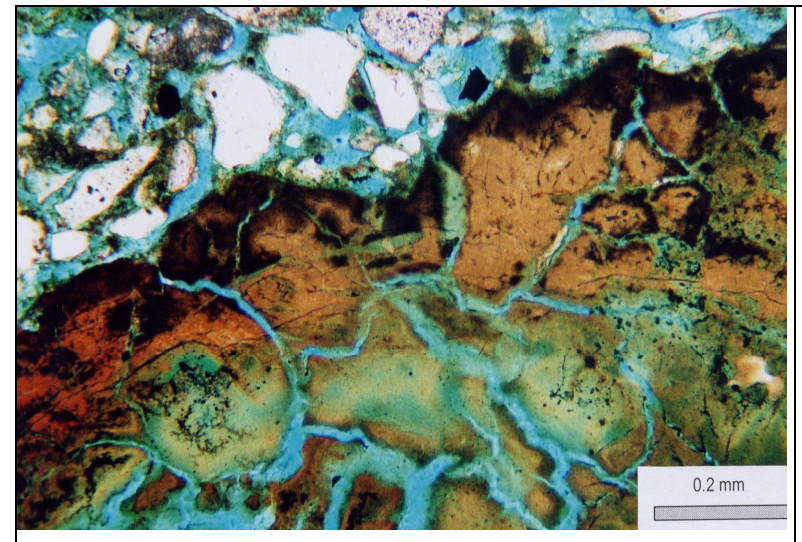

Fifure 3. Detail of lime accumulation with typical retraction fractures in a mortar from Newcastlewest Coach House, Ireland.10X, Plane polars.

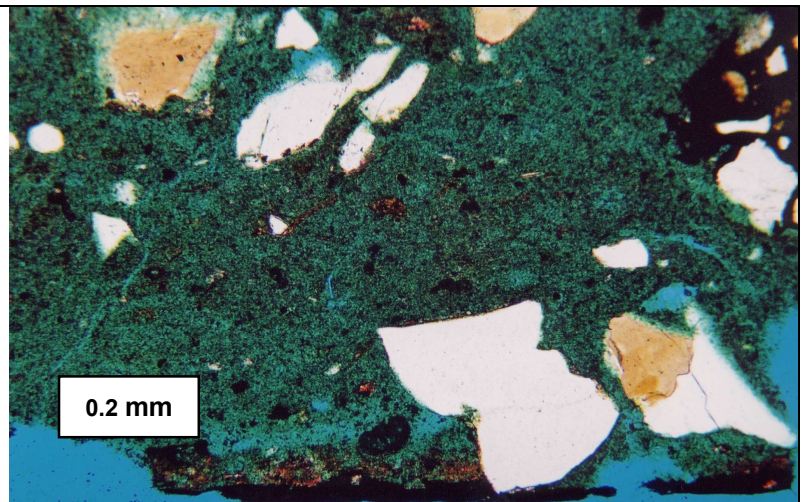

Figure 4: Calcium lime Roman mortar from Calahorra, La Rioja, displaying good adhesion and an absence of significant shrinkage fractures despite the high binder: aggregate ratio, features consistent with a high waterretention capacity for the lime. 10X. Crossed polars.

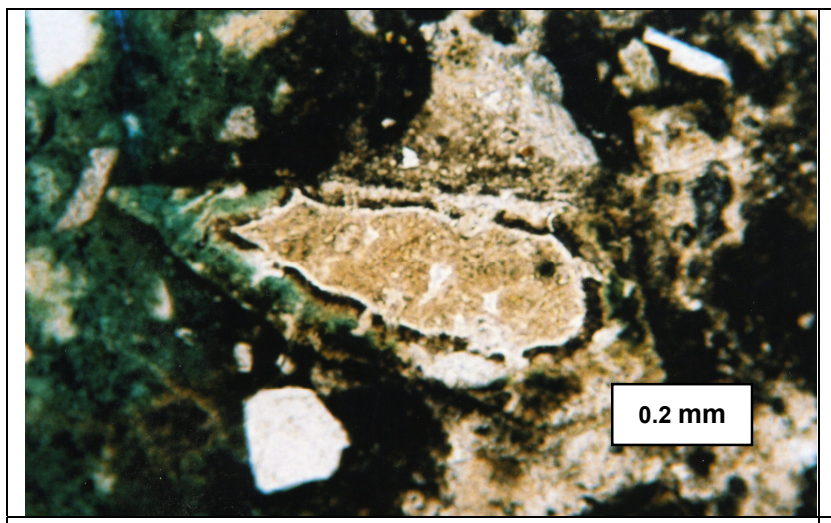

Figure 5. Aggregate-binder reaction, probably due to the exothermic reaction of lime slaking trigered by hot mixing. Lime mortar, Jiggistown House, Ireland. 10X Plane polars.

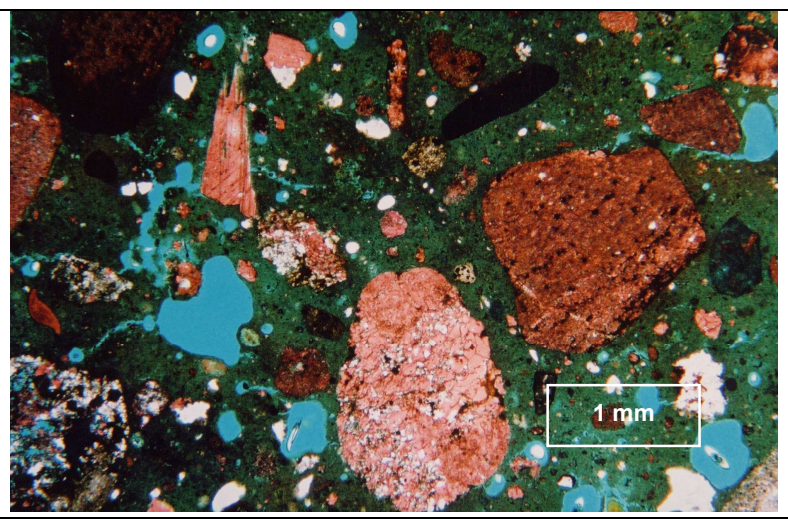

Figure 6. Coarse tufa aggregate of local origin in a Roman mortar from the Contrebia-leukade city wall, La Rioja, Spain. 2X. Plane polars.

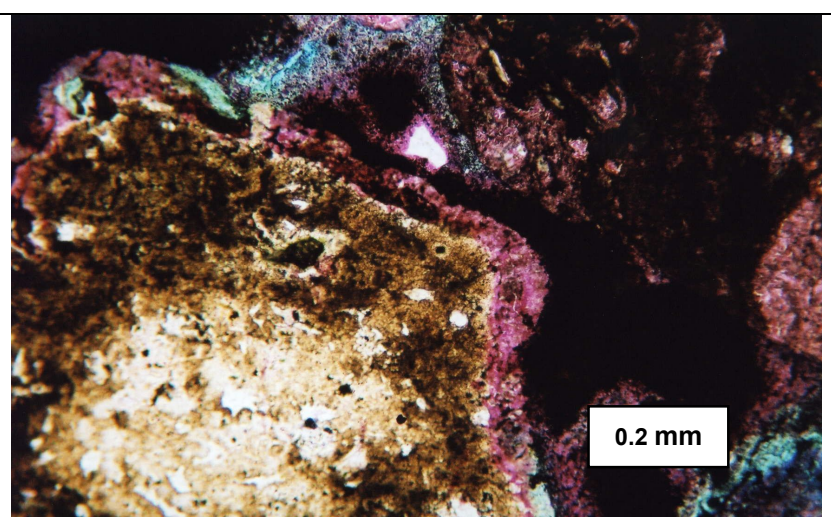

Figure 7. Example of natural mortar hydraulicity due to the presence of pozzolans within the aggregate: Reactive microsilica (chert), naturally present in the aggregate, shows hydraulic reaction with the lime binder. John's Bridge Kilkenny, Ireland. 10X, Plane polars.

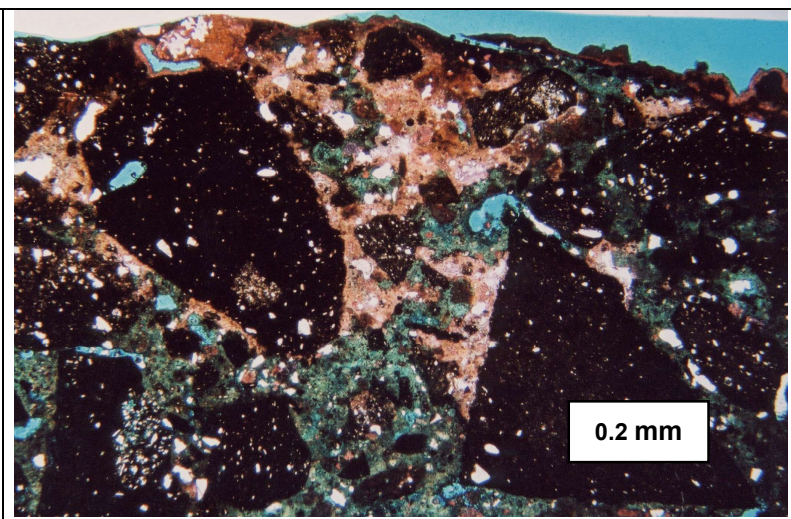

Figure 8. An example of deliberately-induced hydraulicity: ceramic fragments added as pozzolans to a Roman mortar from Calahorra, Spain, displaying hydraulic reaction. 10X, Plane polars. 


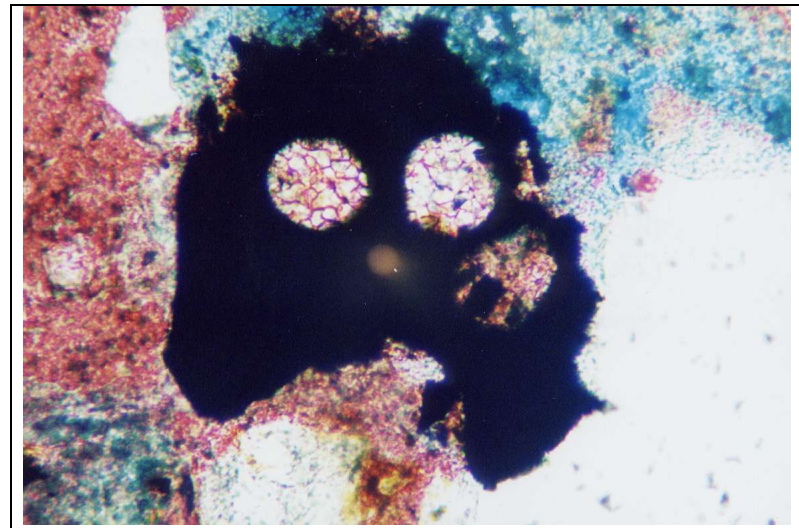

Figure 9. Detail the remains of coal in a $18^{\text {th }}$ century mortar form the Iveragh Markets, Dublin, 40X, plane polars.

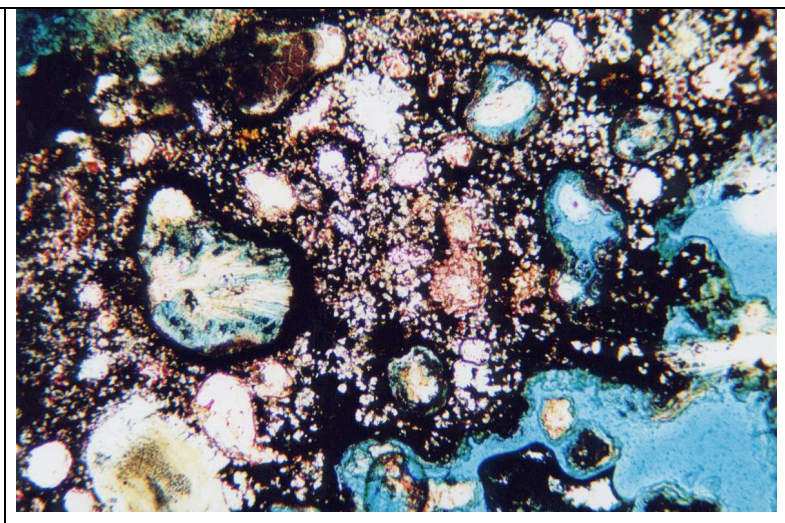

Figure 10. Newformed hydraulic cements due to pozzolanic reaction of coal. Iveragh Markets. Parallel light. 40X, plane polars.

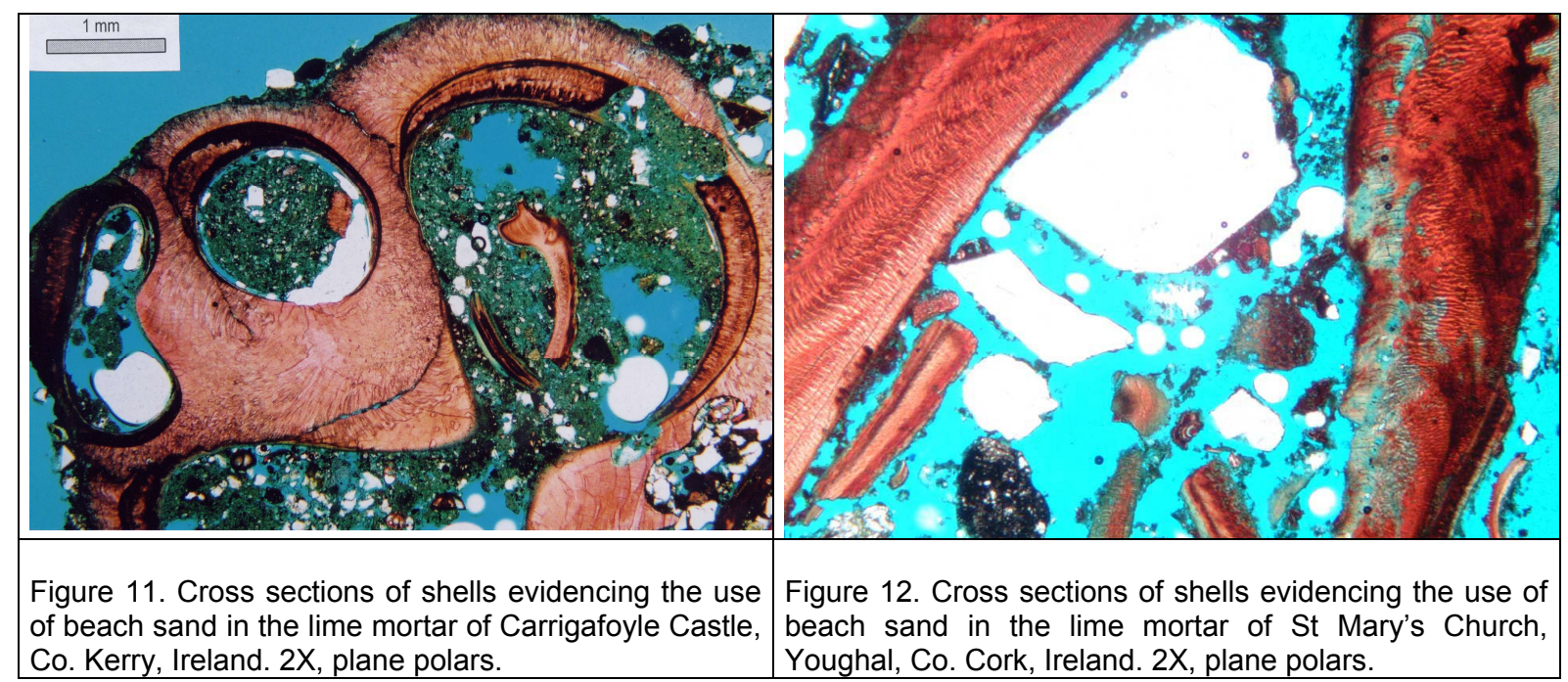

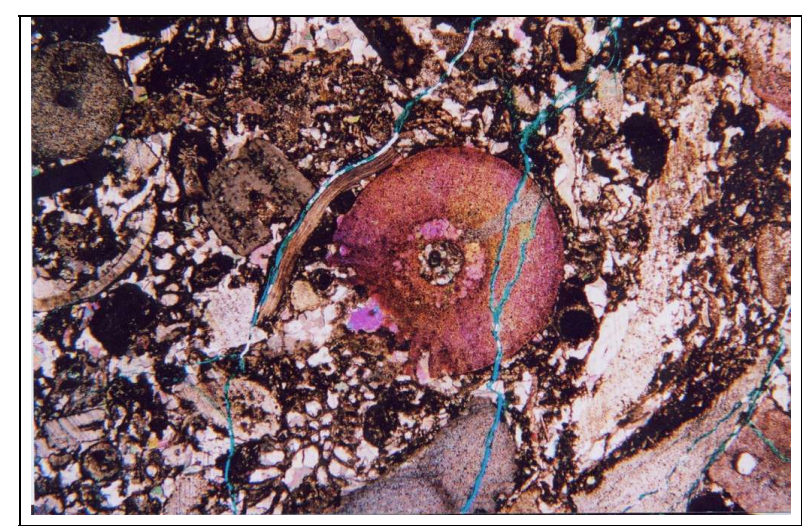

Figure 13. Coarse aggregate of local Carboniferous limestone, Saint James Hospital, Dublin, suggesting a local source for the mortar's aggregate. $2 X$ crossed polars.

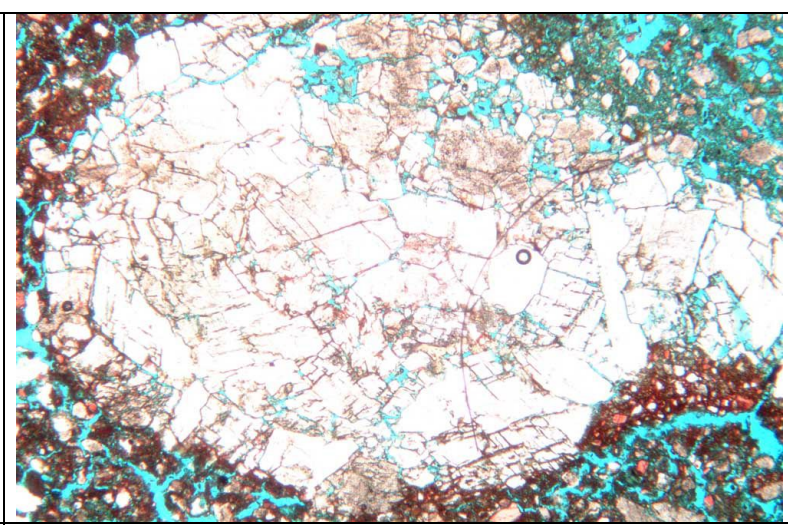

Figure 14. Underburned fragment of dolomitic limestone consistent with the local bedrock, Ardamullivan Castle, Co. Clare, Ireland, thus suggesting a local material source. $2 X$, plane polars. 


\section{PETROGRAPHIC MICROSCOPY VS CERAMIC TECHNOLOGY}

As aforementioned, petrographic analysis is an established method for ceramic investigation that can be used to determine firing technologies, provenance and sources of raw materials of building ceramics. Petrographic analysis of the temper allows the identification of local or foreign ceramic production, while the study of the brick matrix and the amount of pores and cements, coupled to the identification of diagnostic minerals produced during firing, enable to quantify sintering and vitrification and thus estimate firing temperatures. In addition, a petrographic study assists on the assessment of processing and blending of the ceramic ware.

Petrographic evidence of ceramic technology is easier to gather from ceramics made with boulder (glacial) clay or other coarse-grained sediments than from those made with fine-grained sediments such as alluvial clay. In fine grained ceramics, mineralogical identification and the assessment of mineral transformation are difficul to perform due to the low resolution of the petrographic microscope. Therefore, the petrographic study of finegrained ceramics may retrieve very little information, even from a large amount of samples. In these cases, optical methods of higher resolution such as Scanning or Transmission Electron Microscopy with EnergyDispersive X-Ray analysis (SEM-EDAX or TEM) are needed.

\subsection{Brick provenance}

As aforementioned, the use of temper analysis to identify local or foreign production of a ceramic object is a powerful method for coarse-grained ceramics ${ }^{14}$. For example, petrographic analysis of the Rathfarham Castle brick, Dublin, evidenced the presence of the Carboniferous limestones of the Dublin district, therefore suggesting a local source for the brick making sediment. In addition, in the Rathfarham brick, petrographic analysis also evidenced the mineralogical composition of the temper including quartz, chert, sandstone and other rock fragments. These minerals, inherited from the raw clay, were consistent with the geology of the area thus further agreeing with a local source for the brickmaking sediment ${ }^{13}$.

Certain features of a brick's matrix can also suggest possible origins for raw materials. According to Firman et al. ${ }^{30}$, a sandy matrix including very coarse sand and occasional pebbles is characteristic of boulder clays or silty terrace gravels derived from boulder clays. In contrast, fine plastic clays are usually gathered from alluvial, lacustrine, estuarine or canal deposits. In the Rathfarham brick, the sandy brick matrix including a high percentage of non-plastic material such as very coarse sand and occasional pebbles was probably gathered from a glacial deposit. Stoney boulder clays of glacial origin are common in the Rathfarham area, this is therefore a further argument supporting a local origin for the brick.

\subsection{Processing and preparation of the raw clay}

The presence of abundant pebbles in the brick suggests a lack of preparation of the raw clay (the clay was not sieved before it was fired). In addition, petrographic analysis can evidence primary inhomogeneities inherited from the brickmaking sediment, and these suggest a lack of mixing and grounding (for example, the presence of colour inhomogeneities due to mineral segregation). According to Firman ${ }^{30}$, patches of different colour are due to primary inhomogeneities of the brickmaking sediment, their size and shape depend on the character of the brickmaking sediment and the efficiency with which it was subsequently mixed and ground. Segregation of temper and lamination of the matrix were microscopically recorded in the Rathfarham brick. These features are probably inherited from the brickmaking sediment thus suggesting a lack of processing of the raw clay which agrees with the lack of processing deduced from the presence of abundant pebbles.

Thin section petrography can also reveal the addition of temper to the raw clay. Temper can be added to very plastic clays in order to minimise fracturing due to retraction induced as a result of drying and firing. According to Maggetti ${ }^{10}$, one out of four arguments used for the identification of artificially added temper is a bimodal size distribution, therefore, a bimodal temper grading suggests that part of the temper may have been artificially added. 
Additives such as coal, coke breeze, cinder, ashes, organic and domestic waste, slag, wood, straw, chalk, dust, sand, rock fragments; grog (burnt brick waste or burnt clay ground to a powder); pigments; molasses and barium compounds can be mixed with the raw clay for different purposes. ${ }^{5}$. For example, as aforementioned, adding sand, rock fragments or crushed ceramics to plastic clay prevents shrinkage while drying and burning. Microscopic evidence suggests that at Little Coggeshall, Essex, England, sand may have been added to the raw clay as a strengthener, to reduce shrinkage, as early as the twelfth century ${ }^{6}$. Coal, wood, cinder, ashes and other combustible matter were historically added to the raw clay as a fuel to assist firing. Blending fuel with clay for brickmaking was common in London from 1725. Combustible matter and fluxes such as fuel ashes, domestic waste and excrement were used to produce the London brick. These frequently caused dark, cindery spots in the fired brick ${ }^{30}$. This practice was also evidenced through petrographic analysis in the Rathfarham brick (Figure 15).

\section{3 $\quad$ Firing temperature}

Petrographic analysis also allows to quantify sintering and vitrification, and thus estimate firing temperatures which can in turn provide an indication of the type of firing method (kiln or clam firing). According to Tite ${ }^{11}$, open fires or clamps are characterised by fast heating rates and very short times at maximum temperature. 'Maximum temperatures range from $500-900^{\circ} \mathrm{C}$ with a high proportion in the range $600-800^{\circ} \mathrm{C}$ and temperature variations of several hundred degrees are observed within a single firing'. According to the same author, in kiln firing, temperature variations are more restricted, and maximum firing temperatures span the range from 600 to $1000^{\circ} \mathrm{C}$, with a high proportion in the range $750-950^{\circ} \mathrm{C}$. However, effective firing temperatures ranging between 500 and $1200^{\circ} \mathrm{C}$ have also been observed in kiln firings and, here, temperature variations across the bricks are a sign of relatively short soaking times ${ }^{31}$.

Features that inform on firing temperature include birefringence and opaqueness of the brick matrix as well as the amount of glass, sintering and contacts between matrix and temper. In addition, the approximate porosity of the field of view by volume can also give an indication of the firing temperature. According to these, the presence of individual particles with limited contacts, a birefringent matrix and a high porosity are typical of low temperature ceramics (Figure 16). In contrast, a significant degree of interconnection between particles; an opaque matrix with mineral segregation; the occurrence of mineral transformations and overgrowths and a low porosity are features that suggest higher temperatures (Figs 17 and 18), as they indicate that the ceramic body has begun to sintering and vitrifying causing interconnections between particles to increase and porosity to decrease. However, often, historic brick shows a mix of both high and low temperature features due to both the variability of the raw material and the lack of standarisation of the firing process.

Brick made with boulder clay often contains a high proportion of non-plastic material. Much of this material can be sharp, sand-graded quartz or feldspar (thermally resistant relict phases remnant of the raw sediment used for brick making) however, boulder clay often contains abundant rock fragments that can inform, not only on provenance, but also on firing temperatures, on the basis of the mineral transformation they suffer as a result of firing. For example, in the Arch Hall brick ${ }^{32}$, petrographic analysis evidenced mineral transformation: calcite in the siliceous-limestone temper had decomposed forming calcium silicates and leaving porous microcrystalline silica as a remnant. This transformation suggests firing temperatures of, at least, $850^{\circ} \mathrm{C}$ as 'calcite decomposes at approximately $600-850{ }^{\circ} \mathrm{C}$ in a natural clay, and the calcium silicates diopside-wollastonite appear in the range $850-900^{\circ} \mathrm{C}, 33,14$.

\subsection{Physical properties of the fired brick}

The physical properties of a brick are determined by both the nature of the raw sediment and the firing process. As aforementioned, sintering and vitrification during firing cause interconnection between particles to increase and porosity to decrease, therefore, high temperature ceramics are often dense materials of low permeability and high mechanical strength while, in contrast, underfired ceramics can display high porosity and low mechanical strength. In addition, certain features of the raw clay such as the grading and the amount 
and nature of the non-plastic material (sand, silt and peebles) impact the physical properties of the ceramic ware. For example, bricks made with sandy clays of glacial origin are usually porous and tend to achieve lower mechanical strengths, while those made with fine plastic clays of alluvial origin tend to display higher mechanical strengths and a lower porosity.

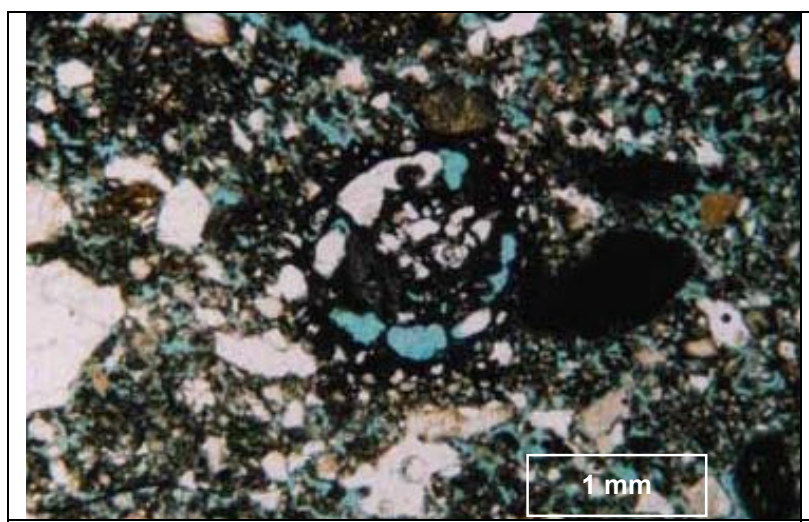

Figure 15. Microphotograph of opaque, cinder-like inclusions suggesting that the raw clay was blended with fuel to assist firing. Rathfarham Castle, Dublin, 2X, plane polars.

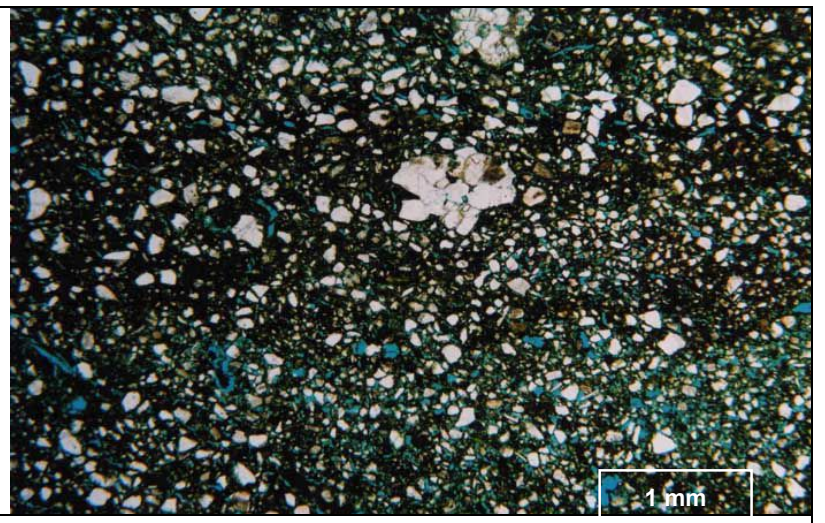

Figure 16. Brick including abundant sand with limited contacts with a birefringent matrix of high porosity, features typical of low temperature ceramics, Arch Hall, Co. Meath, Ireland. X2, plane polars.

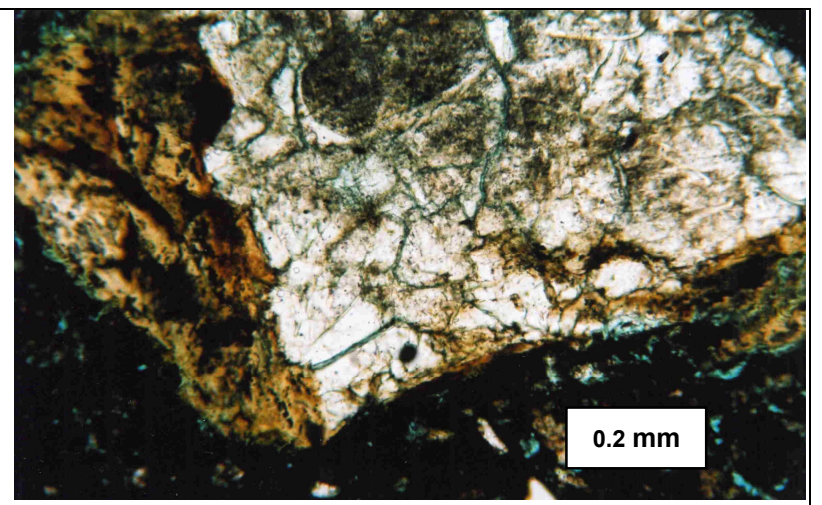

Figure 18. Feldspar transformation during firing, evidence of firing temperatures reaching over $900^{\circ} \mathrm{C}$. Rathfarham Castle, X10, plane polars.
Figure 17. Microphotograph showing typical features of high temperature ceramics including: a significant particle interconnection, an opaque glassy matrix mineral transformation, abundant mineral segregation and a low porosity. Rathfarham. 2X plane polars.

\section{CONCLUSION}

Polarised-light microscopy is an established technique that has been widely applied to heritage materials for the assessment of composition and to diagnose damage. However, this technique can also be used to investigate material technologies including sources of raw materials and processing parameters, an important aspect that has been little investigated. 
The assessment of historic material production technologies is important for two main reasons: First it allows us to produce new, similar, compatible materials to preserve historic fabrics, and second, production technologies arbitrate the physical properties of the material and therefore its quality and durability. In this context, petrographic analysis of a lime mortar binder can provide valuable data on calcination and slaking: two important operations in the manufacture of building limes that govern the reactivity, shrinkage and water retention of a lime binder which will impact mortar's properties such as workability, plasticity and carbonation speed, and these in turn will dictate the ease of execution, durability and strength of a lime mortar. For example, a cohesive lime binder with a high specific surface, low shrinkage and strong aggregate-binder bond, coupled to the presence of aggregate-binder reaction denotes a high reactivity for the lime which agrees with soft burning. In addition, the presence of accumulations of lime binder in lumps indicates either a too short or an incorrect slaking, while even, fully-carbonated, cohesive binder petrofabrics displaying a strong aggregate-binder bond and lacking from lime accumulations and shrinkage fractures would be consistent with a long, full slaking undertaken using the correct amount of water. Furthermore, petrographic evidence of high binder/aggregate ratios, coupled to an absence of shrinkage fractures would be consistent with a high waterretention capacity for the lime, as high water retention avoids shrinkage fracturing due to a high or sudden evaporation. Finally, petrographic analysis can also provide data on mortar mixing, mortar hydraulicity, presence of additions, and problems with execution.

Petrographic analysis also provides evidence of ceramic technology including identification of local or foreign production and processing parameters such as sieving, blending, mixing and firing. In addition, a petrographic study of the ceramic matrix coupled to the diagnosis of mineral phases formed during firing allows to quantify sintering and vitrification and thus determine firing temperatures. For example, the determination of brick temper as local suggest local production for a particular ceramic object, while the identification of combustible fuel evidences that the raw clay was mixed with fuel in order to assist firing. Finally, certain features of the raw clay such as the grading and the amount and nature of the non-plastic material (sand, silt and peebles) inform, not only on the possible origin for the raw material, but also on the type of sediment that was used for ceramic production, and this impacts the physical properties of the ceramic ware.

\section{References}

1. Heinrich, E.W.M. Petrografía microscópica, Omega, Barcelona, 159-164, 1980.

2. T.K. Clough and A.R. Wooley. "Petrography and stone implements" World Archaeology 17,1.1985.

3. Charola, E., Dupas, M., Sheryll, R.P., Freund, G.F. "Characterization of ancient mortars: chemical and instrumental methods". Proc. Symp. on Sci. method. App. to works of Art, Florence, 28-33, 1984.

4. B. Middendorf, J. J. Hughes, K. Callebaut, G. Baronio and I. Papayianni. "Investigative methods for the characterisation of historic mortars-Part 1: Mineralogical characterisation", Materials and Structures, 8, No 8, 761-769, 2005.

5. Pavía S., Bolton J. Stone, Brick and Mortar. Wordwell, Bray, 2000.

6. Firman, R.J. and Firman P.E.. "A geological approach to the study of medieval bricks", Mercian Geologist, $2(3), 299-318,1967$.

7. Heimann, R.B., "Firing technologies and their possible assessment by modern analytical methods" Archaeological ceramics, J. S. Olin \& A. D. Franklin eds., 86-96, Smithsonian Institution Press, Washington DC.,1982.

8. Veniale, F., "Modern techniques of analysis applied to ancient ceramics", Analytical methodologies for the investigation of damaged stones, Pavia, Italy. 1990.

9. Dunham, A.C., "Developments in Industrial Mineralogy: I. The mineralogy of brickmaking", Proceedings of the Yorkshire Geological Society, 49, part 2, 95-104, 1992.

10. Maggetti, M., "Mineralogical and petrographical methods for the study of ancient pottery", First European Workshop on Archaeological Ceramics, 23-35, Rome, 1994,

11. Tite, M.S., "Firing temperature-How and Why?", KVHAA Konferenser, Stockholm, 34, 37-42, 1995.

12. Freestone, I.C., "Ceramic Petrography", American Journal of Archaeology, 99, 111-115,1995.

13. Pavía, S. "Determination of brick provenance and technology using analytical techniques from the physical sciences", Archaeometry, 48, 2, 201-218, 2006. 
14. Maggetti, M., "Phase analysis and its significance for technology and origin" Archaeological ceramics, J. S. Olin \& A. D. Franklin eds., 121-133, Smithsonian Institution Press, Washington DC.,1982.

15. Groot C.J.W.P., Bartos P.J.M. and Hughes J.J. "Historic mortars: characteristics and tests- Concluding summary and state of the art", Proc. Of Int. RILEM workshop on Historic mortars: Characteristics and tests, Bartos, Groot and Hughes eds., RILEM, 443-455, 2000.

16. R. S. Boynton, Chemistry and Technology of lime and limestone, Wiley \& Sons, New York, 1980.

17. Leslie and Hughes, "High-temperature slag formation in historic mortras: evidence for production dynamics in $18^{\text {th }}-19^{\text {th }}$ century lime production from Charlestown". Materials Characterization 53, 181-186, 2004.

18. Perander, T. and Råman, T. Ancient and modern mortars in the restoration of historical buildings, Valtion Teknillinen Tutkimuskeskus (VTT), Helsinki, 1985.

19. Pavía S., Fitzgerald B. and Howard R., "Evaluation of properties of magnesian lime mortar", Structural Studies, Repair and Maintenance of Heritage Architecture IX, C.A. Brebbia and A. Torpiano eds., Vol 83 Transactions on The Built Environment, WIT Press, 375-384, 2005.

20. Leslie A. B. and Hughes J. J. "Binder microstructure in lime mortars: implications for the interpretation of analysis results", Quarterly Journal Of Eng. Geol., 35, 257-263, 2002.

21. Leslie A. B. and Gibbons P. "Mortar analysis and repair specification" Proc. Of Int. RILEM workshop on Historic mortars: Characteristics and tests, Bartos, Groot and Hughes eds., RILEM, 273-280, 2000.

22. Elert K., Rodriguez-Navarro C., Sebastian Pard o E., Hansen E., Cazalla O., "Lime mortars for the conservation of historic buildings", Studies in Cons, 47, 62-75, 2002.

23. Hughes J.J. and Cuthbert S. J., "The petrography and microstructure of medieval lime mortars from the west of Scotland: Implications for the formulation of repair and replacement mortars", Materials and Structures, 33, No 9, 594-600, 2000.

24. Pavía S. and Caro S. "Aplicaciones del estudio petrografico de morteros en la conservacion del patrimonio", Tierra y Tecnología, 28, 56-62, 2006.

25. Binda, L., Baronio, G., Tedeschi C., "Experimental study of the mechanical role of thick mortar joints in reproduced Byzantine masonry", Proc. Of Int. RILEM workshop on Historic mortars: Characteristics and tests, Bartos, Groot and Hughes eds., RILEM, 227-247, 2000.

26. Pavía S., Petrographic examination of historic lime mortars, unpublished research and professional reports 1989-2006.

27. Callebaut, K., Viaene W., Van Balen K., Ottenburgs R., "Petrographical, mineralogical and chemical characterisation of lime mortars in the St Michael's Church (Leuven, Belgium)", Proc. Of Int. RILEM workshop on Historic mortars: Characteristics and tests, Bartos, Groot and Hughes eds., RILEM, 113$123,2000$.

28. Enoch, V.J. The Martello Towers of Ireland, Dublin, 1975.

29. Hughes J. J.and Leslie A. B. "The petrography of lime inclusions of historic lime based mortars", Proc of the $8^{\text {th }}$ Euroseminar on Microscopy applied to building materials, Annales Geologiques des pays Helleniques, Athenes Dept of Geology, 359-364, 2001.

30. Firman, R.J. "The colour of brick in historic brickwork", British Brick Society Information, 61, 3-9, 1994.

31. Wolf, S., "Estimation of the production parameters of very large medieval bricks from St. Urban, Switzerland", Archaeometry, 44, 1, 37-65, 2002.

32. Pavía S. and Roundtree S., "An investigation into Irish historical ceramics: the brick of Arch Hall, Wilkinstown, Co. Meath", Proc. of the Royal Irish Academy, 105C, 6, 221-242, 2005.

33. Peters, T. and lberg, R., "Mineralogical changes during firing of calcium-rich brick clays", Ceramic Bulletin, 57, 5, 503-509, 1978. 